\title{
The Trend Analysis on China's Agricultural Natural Risks and Improvement of the Ability of Disaster Mitigation
}

\author{
Jian Wang \\ Professor, Economics and Trade College, Agricultural University of Hebei, Baoding 071000, China \\ E-mail:wangjian@hebau.edu.cn \\ Lijuan Qiao \\ PhD candidate, Agricultural University of Hebei, Baoding 071000, China \\ E-mail: qiaolijuan820@126.com \\ Yueling Zhang
}

Associate Professor, Economics and Trade College, Agricultural University of Hebei, Baoding 071000, China

E-mail: zhyljmxy@126.com

Junyan Zhao

Lecturer, Economics and Trade College, Agricultural University of Hebei, Baoding 071000, China

E-mail: zhjy@hebau.edu.cn

Zhengjia Wang

Research assistant, Academic Affairs Experimental Center, Agricultural University of Hebei, Baoding 071000, China

E-mail: wangzhengjia927@gmail.com

Rehman Abdur

$\mathrm{PhD}$ Candidate, Economics and Trade College, Agricultural University of Hebei, Baoding 071000, China

E-mail: rahman294@yahoo.co.in

Xing Li

Pre-master, Economics and Trade College, Agricultural University of Hebei, Baoding 071000, China

E-mail: lixing201100@126.com

Received: November 12, 2012

Accepted: December 31, 2012

Online Published: March 7, 2013

doi:10.5430/rwe.v4n1p82

URL: http://dx.doi.org/10.5430/rwe.v4n1p82

The paper was supported by Chinese Education Ministry of Social Science and Humanities Project (No. 12YJAZH138), Philosophy and Social Science Project (HB12YJ001) and Soft Science Project (12457204D-4) of Hebei Province.

\begin{abstract}
In accordance with the concept of the agricultural natural disasters formed in China, by means of over 20 years of major disasters occurred panel data of recorded, it defined and measured the rates of disaster reduction and disaster affected, and gives the interpretation of mitigation agricultural natural disasters. According to the extent and the area


of distribution of a variety of disasters in the losses of crop, use of basic statistical methods to analyze the development trend and the affected area's variation of various disasters. Such as, it discussed the natural disaster's long-term changes in the diversity and complexity of features. Finally, from the perspective of macro policy it studies the responds and mitigation measures to cope with agricultural natural disasters.

Keywords: Natural disaster, Disaster mitigation, Disaster affected rate, Disaster reduction rate, Tendency

\section{Introduction}

China is one of the most serious natural disaster countries in the world. The natural disasters that China suffers from have many characteristics such as diverse types, wide scope of distribution, high frequency, huge losses, etc. "Over the past 40 years, the annual direct economic losses of disasters caused accounting for about 3- 5\% of the gross national product, the average annual death tolls of tens of thousands of people" (Hu Zhenyin, 2012). "Therefore, China has been comprehensively implementing Scientific Outlook on Development, further strengthened legislation as well as the building of systems and mechanisms on disaster prevention and reduction, committed to building on disaster-prevention capacities, encouraged public contribution, and actively participated in international cooperation in this respect." (China Daily, 2009) The environmental disasters and the accidents are the main origins of creating the agricultural natural risks. Throughout human history, natural disasters have played a major role in the economic development and survival of humanity. "Natural disasters include hydro-meteorological disasters and geophysical disasters" (World Disaster Report, 2003)

Agriculture usually is a typical risk industry, because of its development in the natural environment with uncertainty clouded. "Agriculture is a complex system, within which changes are driven by the joint effects of economical, environmental, political, and social forces (Olmstead, 1970; Bryant and Johnston, 1992; M.V.K. Sivakumar, 2006)". However, this article supposed that our research central on agricultural natural risk system use the historical panel data to analyze the effect of environmental disasters. It without consider other environmental factors or the exogenous factors, like political system, laws, policies and social factors and so on.

Agricultural producers first rely on natural environmental conditions. Natural resources and the environmental conditions is also material base on whether a national agricultural production has superiority. When a certain factors change or the emergency occurs in the natural environment, it may bring agricultural harm. Natural environment usually refers to the non-human created material geography space. Natural sunlight, temperature, air, water, soil, wildlife, plants, other natural materials and works of non-human, they constitute the fundamental factors of the natural environment. So that, under background of uncertainty the paper mainly discusses the five kinds of meteorological disasters, such as waterlogged, drought, hailstorm, winterkill, and typhoon, and take advantage over 20 years of statistical data to make some of system analysis. In a macro-aspect we discussed the origin of agricultural production risks, to analyze the natural disasters trends and to explore the hazard mitigation measures, as well as, by means of market countermeasures we strive to achieve compensation for disaster losses.

\subsection{Agricultural Natural Disasters}

The Centre for Research on the Epidemiology of Disasters (CRED) classified an event as a disaster if at least " 10 people are killed and/or 100 or more are affected and/or an appeal for international assistance is made or a state of emergency declared" (CRED, 2000). According to M.V.K. Sivakumar (2006), "clearly, for agricultural purposes only the last part of this definition is applicable." (M.V.K. Sivakumar, 2006) United Nations (UN, 1992) defined a disaster as "a serious disruption of the functioning of society, causing widespread human, material or environmental losses which exceed the capacity of the affected society to cope using only its own resources." It was a suitable interpretation that could be used by agriculture. For agricultural natural disasters usually assumed that disasters only affected the project by reducing yield, although additional costs may be incurred as a result of changing in cost.

In China, the record of disasters in the average crop losses is up to $10 \%$ to compare with the previous year. "To assume that the primary impact of disasters on the project's net benefits is through the impact on agricultural yields," (Mohan Munasinghe \& Caroline Clarke, 1995) this is best for deal with the agriculture sustainable development.

The disaster covered area and affected area is essentially the same meaning as is caused by natural phenomena, such as: hail storm, floods, droughts, typhoon and blizzard brought agriculture losses. To a disaster the covered area refers to crops in $10 \%$ losses, and the affected area refers to crops over $30 \%$ losses. Figure 1 showing, as some kinds of natural disasters regional distribution, if crop losses in excess of 30\% mean that more serious disaster, to reach $70 \%$ of the loss shall be no harvest.

$<$ Insert Figure 1 Here $>$ 
"The natural environment and the agricultural risks can be summed up two big kinds roughly. One involves the agricultural disasters in production process, which are called the natural risks, and the others mainly refer to agricultural management process, which are called the market risks.”(Wang Jian, 2005)

\subsection{Agricultural Natural Disasters Mitigation}

"Mitigation means taking actions to reduce the effects of a hazard before it occurs. The term mitigation applies to a wide range of activities and protection measures that might be instigated from the physical, like constructing stronger buildings to the procedural, like standard techniques for incorporating hazard assessment in land-use planning". (UNDP, p13, 1994)

Suppose, the initial produced disasters scale is what its covered areas (up to $10 \%$ ), and the scale of disasters finally formed (over 30\%) is its affected areas. We can study the correlation of different disasters, on how rely on their changes in different stages of development, and to find that the main impact factors and to seek the measures to deal with. Mitigation purposes are to prevent hazards from developing into disasters altogether or to reduce the effects of disasters, as well as the effort to reduce loss of life and property by reduction the impact of disasters. Thus, as regional distribution of natural disasters and the degree of the loss changed in the gradient, the disaster coverage area should neither exceed the ultimate disaster affected areas, or the disasters covered areas should bigger than its affected areas. That means the disasters have been reduced. Therefore, the difference between the two can be on behalf of the community in the prevention, mitigation and disaster-resistant ability.

"Mitigation also entails the protection of the economy from disasters. Agricultural sectors of the economy are most vulnerable to drought but also to floods, high winds, diseases, pest attack and pollution. Mitigation measures that focus on protecting the most vulnerable elements and activities-the weakest links-in the different sectors of the economy will help protect the achievements of economic development." (UNDP, p17, 1994)

"The mitigation phase differs from the other phases in that it focuses on long-term measures for reducing or eliminating risk. The implementation of mitigation strategies is a part of the recovery process if it is applied after a disaster occurs." (Haddow, George D., Jane A Bullock, 2003). In fact, we are possible to find some rules to fight huge natural disasters. The first is achieved through risk analysis, which results in information that provides a foundation for mitigation activities that reduce risk. The second strengthen infrastructure construction, dredging rivers and reservoirs, constructing roads and bridges, improving construction quality, and so on, which is able to prevent and resist disasters efficiently. And the third is to develop insurance markets that protect financial investment and development of social relief force.

\section{Diversified Natural Disasters of China's Agriculture}

Agricultural production is first dominated by natural condition, environmental variation, zoological and botanical growth of development mechanism. These thunderbolts or the random events from the nature possibly make the agricultural production have economic loss that called agricultural natural risks. The risk of natural disasters is essentially refers to natural damage magnitude, time and their probability distributions.

Chinese agricultural resource wasted or the ecological environment destroyed was also vital for the natural disasters. Although the nation is abundant in natural resources, but the problem of soil erosion and destroying environment are very serious. At present, China soil erosion area is about $357 \mathrm{Km}^{2}$, occupying $37.2 \%$ of the land area. These including every year the water erosion, loosed the soil approximately $5 \times 10^{9}$ tons, nutrients and nitrogen, phosphorus, potassium were washed away approximately a hundred million tons, as well as the wind erosion and the desertification influence. Air pollution farmland scales to 5.333 million hectares, the three wastes pollution farmland amounts to 10 million hectares, the agricultural made chemical pollution farmland amounts to 9.07 million hectares, the agricultural made water quality drops, the pollution which created also amount to 3.3 million hectares, totally above approximately 27.7 million hectares. Just the fertility loss gives in every year more than seven billions CNY, the question was very serious. (Xinhua News Agency, 2010; China State Council, 2011; Daily of Science and Technology, 2012)

The types and the area of disasters are diversified and broad with higher proportion to be affected at final. Its main natural disaster factors over 40 kinds, mainly have the flooding, the rainstorm, the hail, the drought, the gale, the spring cold wave, the low temperature in May, the winter coldly wind and freezing, the plant disease and insect pest, the landslide, the mud-rock flow, the cracks of earth, the avalanche, the typhoon, tsunami and so on. According to the related historical data records, from 206 B.C. to 1949, China had covered big flood 1029 times, drought 1056 times. From 1949 to 1988, there were five floods which affected disaster area over 6 million hectares, drought six times which affected disaster area 12 million hectares above. In 1961, continual great drought affected disaster area 
18.68 million hectares. (Chu Guozhu, C. F. Framingham, Shi Peijun, 1995)

During the 1990s, big flood disasters happened 4 times, that disaster affected area was over 12 million hectares, and in 1991 was 14.61 million hectares, in 1998 was 13.79 million hectares, in 2003 was 12.29 million hectares. Moreover, "general big drought and the waterlogged disaster yearly occurs alternately, most years drought area was bigger than the waterlogged, in the specific year big area drought and waterlogged disaster possible occurrence simultaneously. By natural disaster's influences national grain loss to approximately in average $5 \%$ of yearly grain gross output, the agricultural yearly average disaster rate reaches as high as 14.5\%." (Li Maosong, Li Sen, Li Yuhui, 2004) The main agricultural natural disasters and the loss situation of China since 1990s have been shown in Table 1.

\section{Trends Analysis on Natural Disasters}

Based on above data we can give an initial analysis on the natural disaster's risk, which will bring us a general understanding for the problems and find some tendencies and rules.

\subsection{The Natural Disaster Covered Is Increasing}

The natural disaster is inevitable with uncertainty, in agriculture over 21 years, an average covered disaster area is nearly 47.36 million hectares in the national level, but the disaster finally affected which is nearly 25.03 million hectares annually in average. The average disaster finally affected in China is higher than half of the disaster covered. This data refers to the five kind's main agricultural natural disasters, such as waterlogged, drought, hailstorm, winterkilling, and typhoon. Therefore, other agricultural natural damages have not been included, for instance plant disease and insect, grass evil, rodents harm, etc.

$<$ Insert Figure 2 Here $>$

From the Figure 2, we easy to find among the natural disasters drought covered area is bigger than flood covered. However, in recently years the drought area is tending to reduce a little, the flood and freezing areas are tended in increasing. Typhoon in statistics as a new-recorded natural disaster of China since 1994, but its influence to Chinese agriculture has been increasing. We can say, therefore, the environmental hazards and uncertainties are in increasing.

\subsection{Basic Statistical Analysis}

Natural disaster occurrence are mainly exogenous factors or absolutely. But its mitigation is mainly endogenous function. In fact, the natural environmental deterioration and absent ecologic protection are serious problems at present. In theory, risk is always in positive relation with expected utility or expected revenue of people. Therefore, higher exaction from nature should return with higher risk. In another side, risk is usually in reciprocal with information that is experience and knowledge. The ecological civilized knowledge is a set of this kind of information. It usually includes that people how to prevent or to fight with natural calamities. The ability or effects of people to prevent and to fight with natural disaster becomes a contemporary social function. With the statistic data, we can give an initial analysis for the cases of natural disaster reduction and prevention.

Assume to use disaster covered area subtracts its affected area, we can measure the level of disaster reduction or mitigation. Seeing from a macro level, preventing and resisting natural disaster is an important economic achievement, which may use disaster reduction area to express. So that, defined F (D, t) to express each kind of disasters collected variation following each years $(t)$, shows in Figure 1, the unit is disaster covered area of million hectares. Then we can see the effect variation in dynamic to deduct and to prevent the natural disasters.

$<$ Insert Table 2 Here $>$

By means of the descriptive statistics, we can find the average of disasters covered areas and extreme values, etc. To compare those disasters areas covered with disasters and affected areas, by Table 2 and Table 3, we can find some significant issues. From the 17 years statistics, since there was the data on typhoon in 1994, the macro-data manifested from disasters produced to its final formed over 30\% crop losses that the scale of disaster was greatly reduced, disaster reduction close to more than one half.

$<$ Insert Table 3 Here>

Suppose, the rate of disaster reduction is a concept of showing the disaster mitigation, to compare it's occurred areas in different cases. If use $\Delta F(D, t)=F(D c, t)-F(D a, t)$ to express this measured effect in area, thus we can define a ratio of natural disaster reduction by $R_{r}=\Delta F(D, t) / F(D c, t)=1-F(D a, t) / F(D c, t)$. Here $F(D c, t)$ expresses annual disaster covered area, $\mathrm{F}(\mathrm{Da}, \mathrm{t})$ expresses annual disaster final affected area, and assume there is always existed $F(D c, t) \geq F(D a, t)>0$. So that, we can name $R_{a}=F(D a, t) / F(D c, t)$ as a rate of the disaster affected, and both $R_{r}+R_{a}=1$, and $1 \geq R_{r} \geq 0,1 \geq R_{a} \geq 0$. 
Following peoples experience collection and a national capacity improving in knowledge and infrastructure to treat with natural disaster, in theoretical tendency of $\Delta \mathrm{F}(\mathrm{D}, \mathrm{t})$ should be a form of trumpet. At the same time, the rate of disaster reduction $\left(\mathrm{R}_{\mathrm{r}}\right)$ should tend to a positive slope while the rate of disaster affected $\left(\mathrm{R}_{\mathrm{A}}\right)$ should be a negative slope in long run tendency. We can show those in figure 3 , but the explanation to combine with practice may be very complex, because of their possible is the reason of social economy, disaster scale, politics or history. For example, during the era of Cultural Revolution we loosed the data of several years. Therefore, we certainly hope to find some better analyzing technologies and to analyze the problems by data statistics. In fact, the natural disaster covered is brimming uncertainty, the idea rule is difficult to find, but table 4 shown that rates of disaster reduction have increased in tendency.

$<$ Insert Table 4 Here $>$

\subsection{The Development Trends of the Governance to Five Natural Disasters}

(1) The droughts: In figure 3 the curve DC shows drought occurring area yearly change, DCT shows its tendency of variation, DA represents drought affected area, and the curve DAT is the tendency of drought affected. After 2003, drought covered and finally affected disaster area has being slope down obviously.

$<$ Insert Figure 3 Here $>$

(2)The floods: Recently years, flood is tending to go up, and in some significance, waterlogged disaster is a current big risk to China's agriculture. Hydraulic construction has made great contribution both in fighting with drought and in preventing big flood. Its aim to reduce drought covered and affected area, and to control the flood disaster formation. Figure 4 shows the tendency of flood variation, the curves FC and FA represent flood covered and affected areas separately, and FCT, FAT are respectively shown their tendencies.

$<$ Insert Figure 4 Here $>$

(3)The typhoon: As a natural disaster in recently years, typhoon is an increasing tendency especially in the coastal region of south China. Its covered area is over freezing affected in average, but it is more difficult to prevent than freezing damage. 17 years of records on typhoon showed us a very dangerous of natural disaster to agriculture. In Figure 5, typhoon disaster entering 21 century has quickly increased. The curves TC, TA represent each year typhoon disaster covered and affected area, and the related curves TAT, TCT can help us to understand their tendencies.

$<$ Insert Figure 5 Here $>$

(4) Freezing, wind and hail: Otherwise, the natural disasters that come from hailstorm and winterkilling is also tended to increase in recent years. The annual wind and hail covered is 4.67 million hectares and the freezing covered is 4.25 million hectares in average. However, those two kind disasters affected area is relatively lower than the disasters covered in average. That means the disaster affected area slopes down evident the disaster reduction ability enhancing, which can be expressed by disaster reduction rates as in Figure 6.

$<$ Insert Figure 6 Here $>$

\section{Conclusion and Countermeasures}

\subsection{The General Trend}

We can sum up the five kinds of natural disasters covered and affected areas to use the data since the year of 1990. The Figure 7 illustrates that in recent years the total disaster covered area has a tendency of going up, and the total disaster affected area has a tendency of sloping down. This may be the natural disasters to enter into a highly occurring new period, and the capacities of disaster reduction in China have reached a new level, so that the two curves show trumpet-type trend.

To compare the Figures 3-5, we can make more detail illustration. About the drought disaster we find it is a special case, that both drought disaster covered and affected areas have been the tendencies of go down. After 1990s, the Figure 3 shows an inverse trumpet trend, only from the data aspect to make logical analysis it seems to indicate that hydraulic construction has made the disaster covered area reduced, but the weakened irrigation systems did not effect to fight with big drought. From figure 4 shows that both flood covered and affected areas are increasing. However, it is a trumpet shape that illustrates the effects to fight flood is clearly improved these years. The rates of disaster reduction and mitigation can help us to understand the consequences better.

$<$ Insert Figure 7 Here $>$

In Figure 7 we can find, there are existed two appearances of general tendency and periodic variations for five 
disasters since 1994. Polynomial regression trend curves describe the occurrence of disasters in recent years on the rise, but the disaster affected areas relative decline.

\subsection{Changes in the Long-term}

As a complementary, taking the main disasters drought and flood as examples, because of there had been long term records for them since 1952. In Figure 8, the polynomial regression trend curves describe the nearly half a century of changes in drought and flood disasters occurred areas and affected areas, which shows the tendencies for a longer period.

$<$ Insert Figure 8 Here $>$

Since 1990s the natural environment seems become worse year by year. In the 21 century, especially in recent years the natural disasters have tended to increasing. Figure 9 has drawn the $\mathrm{Rr}$ and $\mathrm{Ra}$ curves, and according to the data of natural disasters covered and affected areas in units million hectares. The trend curves imply that natural disasters resist changes and mitigation capabilities. These relative variations only refer to the disasters of drought and flood since 1952.

$<$ Insert Figure 9 Here $>$

When the disaster reduction rate is greater than the disaster affected rate, which means $\mathrm{Rr}>\mathrm{Ra}$. That shows a higher ability and effect to cope with disasters, as well as natural disasters affected in a given year is smaller or easy to mitigate. From another perspective, if droughts and floods are especially severe or agriculture become more vulnerable, then $\mathrm{Rr}<\mathrm{Ra}$. However, as we know natural disaster formation is affected by many factors actually, which is very complex. Objectively, Table 5 shows that the correlation coefficients of five kinds disasters between its covered and affected areas are very high, which seem to indicate the disasters affected mostly rely on its natural formation and occurrences.

$<$ Insert Table 5 Here $>$

\subsection{The Diversity and Governance Complexity of Natural Disasters}

Typhoon reduction rate is increasing, and its affected rate is go down which has been appearance a periodic variation. Wind and hail through a long period disaster covered rate larger than its reduction rate, now the reduction rate tends to increase. In China, fight with freezing effect shows better, and the rate of affected disaster in general lower than its reduction rate in long run, and seems easy mitigation. Drought is a big problem to puzzle Chinese agricultural development, since the end of 1990s its reduction rate has been go down and its disaster affected rate tended to go up, shows a periodic variation. Recent years, the case has being changed, and the countermeasure should be enforcing the irrigation system construction. Floods are heavy disaster in China, and the reduction rate is tended to go down for nearly ten years. However, floods disaster affected rate in general larger than its reduction rate, so current cope with disasters, mainly resist floods and its governance.

Beside above five kinds of main natural disasters that we have discussed, the article lack of consideration on plant diseases and insects, grass evil and rat damages. We have found that plant disease and insects has been over prevented since 1992, the prevented area keeps larger than the covered area of disaster. The grass evils prevention effect is more obvious, even the covered areas surpassed its prevented. The other problem is rat harm, in a long term the rat prevented area is far from it has covered area. Those need us to give a more attention. (Wang Jian, 2005) Some disasters occur isolated is easier governance, however, when multiple of natural disasters complex intertwined, some can be taken advantage, some might mitigate, but some changed into the huge contradictions, that we have to take risk aversion measures.

\subsection{Countermeasures}

On the stability of agricultural production, except natural disaster influences, the human factors also influences ecological environment. In natural environment, between non-biotic and the biotic factors, the non-biotic factors as well as the biotic factors themselves are used mutually contact, constraint or depends on each others, by these intriguing factors constituted inalienable complex synthetically system, which is called the natural ecosystem. When consider that artificial influences to the ecosystem, it becomes a social ecoeconomic system. Because of ecosystem factor constitutions, if there were some factors or certain factors have changed, other factors will have a series of chain-reactions, thus will cause the natural environment changes. The entire natural ecosystem has come now under humanity's serious influence, beside the atmosphere greenhouse effect made the earth climate warming the agricultural production to its ecological environmental influences and the destruction looked that is also very serious.

The agriculture is the foundation of the national economy, and it is a weak industry with multiple natural risks. 
Especially it is closed related with natural reproduction and social economic reproduction. Improve the ability to resist natural disasters of agriculture is the major topics in the socio-economic development and construction in China. We should strengthen the construction of information, early warning, infrastructure, social security systems, social organizations and the reaction ability.

(1) Information construction and management. Studying of stability problem of agricultural system, first we should inspect the risk and the uncertainty in the agricultural development. Only recognizing risks, we can against them. Risk identification need to seek for the risk initial source and embark from the agricultural natural disasters and the uncertainty realistic background, taking the system science and theory of the agricultural economics management as the instrument. Therefore, information construction is most important contribution to the identification of disaster, early warning prevention, disaster response literacy, as well as information about the cultivation of related social organization. It's able to use modern information technology to develop every kind of professional information channels.

(2) Infrastructure construction. To prevent and fight with natural disaster need huge energy and material, it usually is passive but is the most important defense force. In some significance, learn to deal with or utilize natural disaster is also important. To fight with flood and drought has long history in China. Such as, take flood protection and irrigation, Governance Mountain and river management combined. Chinese people to fight with natural calamities during the past 50 years have made great achievements, but compared with the needs of modernization, there is a big gap.

(3) Promote technological advances in agriculture. Development of disaster prevention, mitigation, and environmental protection technology is very important. To promote drought, water logging, sand-fixing, anti-cold plant and animal species research by use of modern bio-technology. Adjust and optimize the structure of agricultural production, restore vegetation and improve the ecological environment. (Dept. of Science and Technology Education, 2006)

(4) Social security system. "To face with natural disaster, a cover work is plan ahead for disasters."(The Leading Edge, 2006) The planning system, the system of financial funds, social organization and mobilization of actions mechanism, ecological environmental compensation and disaster relief system, and so on, established an agricultural risk macro management system. "Agricultural risk management relies on an optimal combination of technical and financial tools" (Ramiro Iturrioz, 2009). Based on risk management study, development of the agricultural insurance market has played the role of the market in agricultural risk spread and transfer. Insurance only part of solution, connect to technology progress and enforcing infrastructure construction, to make reasonable decision on the investment and budget will be optimal choice to deal with different natural disasters. (Natural Disasters in Australia, 2002)

Final, disasters study may include disaster forecasting, preventing, reduction or mitigation, transfer and disperse as well as disaster relief, they are all belong to disaster management. Because natural disaster occurring is usually inevitable, by means of modern technology people trying to give a forecasting, as we known that information is the first necessary condition. To prevent disaster except prerequisite information, an ample condition is the social infrastructure. Therefore, improve the ability to fight natural calamities should be enforcing risk management and better utilizing above two conditions. Without information, the disaster risk prevention will become difficult, which it will be a game in the existence of uncertainty. Weaken infrastructure could not fight to huge natural disaster, and to deduct the bigger damage. Even west scholar thinks that the management of disaster risk has taken an important part in disaster reduction, relief, transferring and dispersing, which is a powerful social function of a national economic system. (Natural Disasters in Australia, 2002) But in China, state should take disaster prevention system construction in the first place, to allocate financial funds as public goods, because of huge natural disasters do not driven by market forces alone can solve the external uncertainties, emergency plans are necessary, but infrastructure construction must be unremittingly.

\section{References}

A.W. Coburn, R.J.S. Spence, \& A. Pomonis. (1994). Disaster Mitigation $\left(2^{\text {nd }}\right.$ ed.). Cambridge Architectural Research Limited. The Oast House, Malting Lane, Cambridge, United Kingdom. UNDP Disaster Management Training Program.

China Daily. (2009). Actions for disaster prevention and reduction. [Online] Available: http://www.chinadaily.com.cn/cndy/2009-05/12/content_7765642.htm

China State Council. (2011). State Environmental Protection Plan of the "12th Five-Year". NO.42. [Online] 
Available: http://www.china.com.cn/policy/txt/2011-12/21/content_24206929.htm (December 15, 2011)

Chinese Agriculture Yearbook. (1991-2011). Chinese Agricultural Publishing house.

Chu, Guozhu, \& C. F. Framingham. (1995). Agricultural Insurance: Theory, Experience and Problems. Chinese Agricultural Publishing House, 2, 2.

Daily of Science and Technology. (2012). China "poison ground" occupation $20 \%$ of farmlands need to governance repair imminent. [Online] Available: http://www.chinanews.com/gn/2012/06-05/3939722.shtml (Jun 5, 2012)

Dept. of Science and Technology Education, China Ministry of Agriculture. (2011). "The 12th Five-Year Plan" of agricultural science and technology development (2011-2015). [Online] Available: www.moa.gov.cn/ztzl/.../hyfz/201112.htm

George Haddow, Jane Bullock, \& Damon P. Coppola. (2010, Sep.). Introduction to Emergency Management (4th ed.). Butterworth-Heinemann.

$\mathrm{Hu}$, Zhenyin. (2012). Concerned about the problem of natural disasters, innovative disaster reduction and relief mechanism. [Online] Available: http://www.hbmzt.gov.cn/xxgk/ywb/jzjj/njxx/201207/t20120730_133068.shtml (July 30, 2012)

Li, Maosong, Li, Sen, \& Li, Yuhui. (2004). Analysis of Flood Disaster in the Past 50 Years in China. Chinese Journal of Agrometeorology, 25(1).

M.V.K. Sivakumar. (2006). Natural Disasters and Their Mitigation for Sustainable Agricultural Development. Management of Natural and Environmental Resources for Sustainable Agricultural Development. Proceedings of a Workshop. February 13-16, 2006, Portland, Oregon. PDF, pp. 172-190.

Mohan Munasinghe, \& Caroline Clarke. (1995). Disaster prevention for sustainable development: economic and policy issues. A report from the Yokohama World Conference on Natural Disaster Reduction. Copyright $\bigcirc 1995$ The International Bank for Reconstruction and Development/The World Bank, pp. 70-73.

Natural Disasters in Australia---Reforming mitigation, relief and recovery arrangements: A report to the Council of Australian Governments by a high level officials' group August 2002. [Online] Available: www.ema.gov.au/agd/EMA/rwpattach.nsf

Ramiro Iturrioz. (2009). Agricultural Insurance. (C) 2009 The International Bank for Reconstruction and Development/The World Bank, primer series on insurance issue. [Online] Available: www.worldbank.org/nbfi (November 12, 2009)

Shi, Peijun. (1995, July). The Natural Disasters Constructions Works for Disaster Reduction and Sustainable Development of China. Journal of Natural Resources, 10(3), 267-278.

The Leading Edge. (2006). 6(3), Spring. [Online] Available: www.Leading Edge Alliance.com

Wang, Jian. (2005, Dec.). Agricultural Production and Operation Risk Management Theory and Methods. Chinese Education Culture Publishing House.

World Disaster Report. (2003-2011). International Federation of Red Cross and Red Crescent Societies 17, Chemin des Crêts, P.O. Box 372. CH-1211 Geneva 19, Switzerland. [Online] Available: www.ifrc.org

Xinhua News Agency. (2010). The remote sensing survey found that: nearly $40 \%$ of the total land area of the total national soil erosion. [Online] Available: http://news.cntv.cn/20101128/102981.shtml (November 28, 2010) 
Table 1. Main natural disasters covered and final affected in China since 1990 (Unit: 106 hectares)

\begin{tabular}{ccccccccccc}
\hline \multirow{2}{*}{ Year } & \multicolumn{2}{c}{ Typhoon } & \multicolumn{2}{c}{ Wind and hail } & \multicolumn{2}{c}{ Freezing } & \multicolumn{2}{c}{ Drought } & \multicolumn{2}{c}{ Flood } \\
& Areas & Areas & Areas & Areas & Areas & Areas & Areas & Areas & Areas & Areas \\
\hline 1990 & 0 & 0 & 6.35 & 3.42 & 2.14 & 0.99 & 18.17 & 7.81 & 11.80 & 5.60 \\
1991 & 0 & 0 & 4.25 & 2.02 & 1.71 & 0.62 & 24.91 & 10.56 & 24.60 & 14.61 \\
1992 & 0 & 0 & 5.23 & 2.32 & 3.71 & 2.06 & 32.98 & 17.05 & 9.42 & 4.46 \\
1993 & 0 & 0 & 6.63 & 3.64 & 4.72 & 2.23 & 21.10 & 8.66 & 16.39 & 8.61 \\
1994 & 1.58 & 0.78 & 3.79 & 2.14 & 1.92 & 0.67 & 30.42 & 17.05 & 17.33 & 10.74 \\
1995 & 1.30 & 0.37 & 4.48 & 2.08 & 3.58 & 1.79 & 23.46 & 10.40 & 13.06 & 7.63 \\
1996 & 2.24 & 0.97 & 4.15 & 2.12 & 2.05 & 0.90 & 20.15 & 6.25 & 18.15 & 10.85 \\
1997 & 1.72 & 0.68 & 6.21 & 3.63 & 2.29 & 0.83 & 33.51 & 20.01 & 11.41 & 5.84 \\
1998 & 0.21 & 0.10 & 4.95 & 3.23 & 8.67 & 3.10 & 14.24 & 5.06 & 22.29 & 13.79 \\
1999 & 0.59 & 0.32 & 4.18 & 2.36 & 6.63 & 2.69 & 30.16 & 16.61 & 9.016 & 5.07 \\
2000 & 1.72 & 1.08 & 4.03 & 2.24 & 2.80 & 1.03 & 40.54 & 26.78 & 7.32 & 4.32 \\
2001 & 1.10 & 0.65 & 3.63 & 2.06 & 2.98 & 1.78 & 38.47 & 23.70 & 6.04 & 3.61 \\
2002 & 0.85 & 0.47 & 7.48 & 3.83 & 4.21 & 2.29 & 22.21 & 13.25 & 12.38 & 7.47 \\
2003 & 1.17 & 0.72 & 4.79 & 2.93 & 4.48 & 2.11 & 24.85 & 14.47 & 19.21 & 12.29 \\
2004 & 0.69 & 0.21 & 5.80 & 2.19 & 3.71 & 1.67 & 17.25 & 8.48 & 7.46 & 3.75 \\
2005 & 4.45 & 1.97 & 2.98 & 1.64 & 4.43 & 1.84 & 16.03 & 8.48 & 10.93 & 6.05 \\
2006 & 2.95 & 1.67 & 4.39 & 2.14 & 4.91 & 2.84 & 20.74 & 13.41 & 8.10 & 4.57 \\
2007 & 2.09 & 0.86 & 2.99 & 1.42 & 1.81 & 0.67 & 29.39 & 16.17 & 10.46 & 5.10 \\
2008 & 2.31 & 0.94 & 4.18 & 2.12 & 14.70 & 8.72 & 12.14 & 6.80 & 6.48 & 3.66 \\
2009 & 1.146 & 0.48 & 5.49 & 2.94 & 3.67 & 1.45 & 29.26 & 13.20 & 7.61 & 3.16 \\
2010 & 0.34 & 0.17 & 2.18 & 0.92 & 4.12 & 1.44 & 13.26 & 8.99 & 17.52 & 7.02 \\
\hline
\end{tabular}

Note: Data source "China's planting information nets" http://zzys.agri.gov.cn/.

Table 2. The partial main parameters of the descriptive statistics on disaster covered

(Unit: $10^{6}$ hectares, based on Table 1)

\begin{tabular}{cccccc}
\hline Parameters & Typhoon & Wind and hail & Freezing & Drought & Flood \\
\hline Average & 1.556235 & 4.452941 & 4.527059 & 24.47529 & 12.04506 \\
Value (Min, Max) & $(0.21,4.45)$ & $(2.18,7.48)$ & $(1.81,14.7)$ & $(12.14,40.54)$ & $(6.04,22.29)$ \\
\hline
\end{tabular}

Note: Caculated by Table 1.

Table 3. The partial main parameters of the descriptive statistics on disaster affected

(Unit: $10^{6}$ hectares, based on Table 1)

\begin{tabular}{cccccc}
\hline Parameters & Typhoon & Wind and hail & Freezing & Drought & Flood \\
\hline Average & 0.731764706 & 2.352352941 & 2.107058824 & 13.47705882 & 6.76 \\
Value (Min, Max) & $(0.1,1.97)$ & $(0.92,3.83)$ & $(0.67,8.72)$ & $(5.06,26.78)$ & $(3.16,13.79)$ \\
\hline
\end{tabular}

Note: Caculated by Table 1. 
Table 4. The rates of disaster reduction $\left(R_{r}=\%\right)$

\begin{tabular}{llllll}
\hline Year & Typhoon & \multicolumn{1}{c}{ Wind and hail } & \multicolumn{1}{c}{ Freezing } & Drought & \multicolumn{1}{c}{ Flood } \\
\hline 1990 & 0 & 0.461417 & 0.537383 & 0.570171 & 0.525424 \\
1991 & 0 & 0.524706 & 0.637427 & 0.576074 & 0.406098 \\
1992 & 0 & 0.556405 & 0.444744 & 0.48302 & 0.526539 \\
1993 & 0 & 0.45098 & 0.527542 & 0.589573 & 0.47468 \\
1994 & 0.506329 & 0.435356 & 0.651042 & 0.439513 & 0.380265 \\
1995 & 0.715385 & 0.535714 & 0.5 & 0.556692 & 0.415773 \\
1996 & 0.566964 & 0.489157 & 0.560976 & 0.689826 & 0.402204 \\
1997 & 0.604651 & 0.415459 & 0.637555 & 0.402865 & 0.488168 \\
1998 & 0.52381 & 0.347475 & 0.642445 & 0.644663 & 0.381337 \\
1999 & 0.457627 & 0.435407 & 0.594268 & 0.449271 & 0.437666 \\
2000 & 0.372093 & 0.444169 & 0.632143 & 0.339418 & 0.409836 \\
2001 & 0.409091 & 0.432507 & 0.402685 & 0.383936 & 0.402318 \\
2002 & 0.447059 & 0.487968 & 0.456057 & 0.403422 & 0.396607 \\
2003 & 0.384615 & 0.388309 & 0.529018 & 0.417706 & 0.360229 \\
2004 & 0.695652 & 0.622414 & 0.549865 & 0.508406 & 0.497319 \\
2005 & 0.557303 & 0.449664 & 0.58465 & 0.470992 & 0.446478 \\
2006 & 0.433898 & 0.512528 & 0.421589 & 0.353423 & 0.435802 \\
2007 & 0.588517 & 0.525084 & 0.629834 & 0.449813 & 0.512428 \\
2008 & 0.593074 & 0.492823 & 0.406803 & 0.439868 & 0.435185 \\
2009 & 0.581152 & 0.464481 & 0.604905 & 0.548872 & 0.584757 \\
2010 & 0.5 & 0.577982 & 0.650485 & 0.322021 & 0.599315 \\
\hline
\end{tabular}

Note: Caculate by Table 1.

Table 5. The correlation coefficients of 5 disasters between its covered and affected areas

\begin{tabular}{lcccc}
\hline & Typhoon Affected & $\begin{array}{c}\text { Wind and hail } \\
\text { Affected }\end{array}$ & Freezing Affected Drought Affected & Flood Affected \\
\hline $\begin{array}{l}\text { Typhoon Covered } \\
\text { Wind and hail } \\
\text { Covered }\end{array}$ & 0.9689 & & & \\
Freezing Covered & 0.9121 & & \\
Drought Covered & & 0.9634 & \\
Flood Covered & & & 0.9333 & \\
\end{tabular}

Note: Calculated by Table 1.

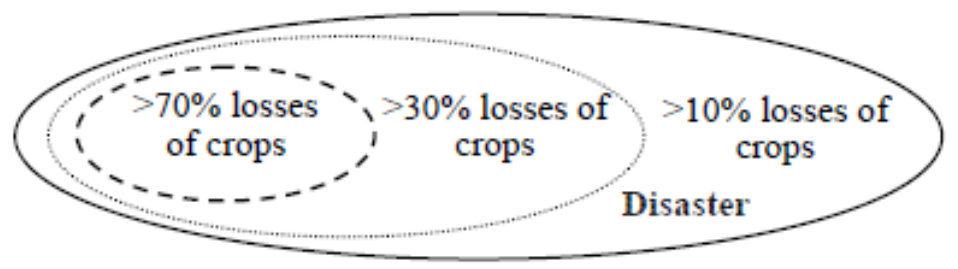

Disaster covered area refers in $10 \%$ crops losses, affected area refers over $30 \%$ crops losses, and over $70 \%$ crops losses the area means the hardest hit.

Figure 1. Contrast different crop harvest circumstances and define the concepts of disaster in area as units 
Five disasters covered areas

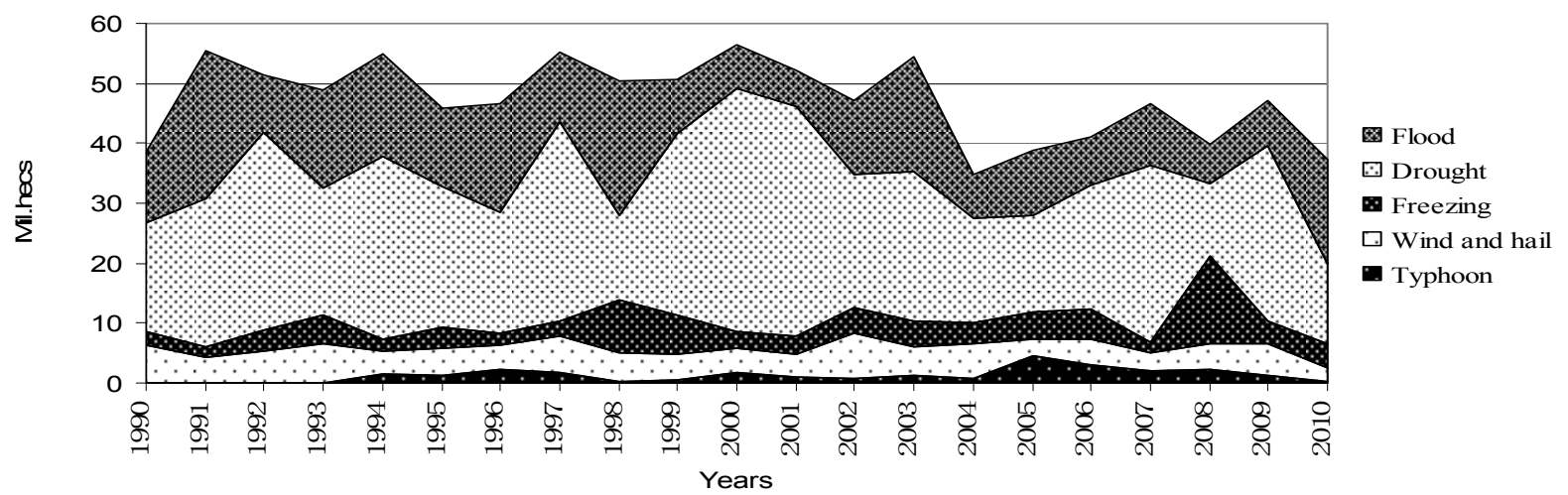

Figure 2. Five kinds of main agricultural natural disasters yearly covered area

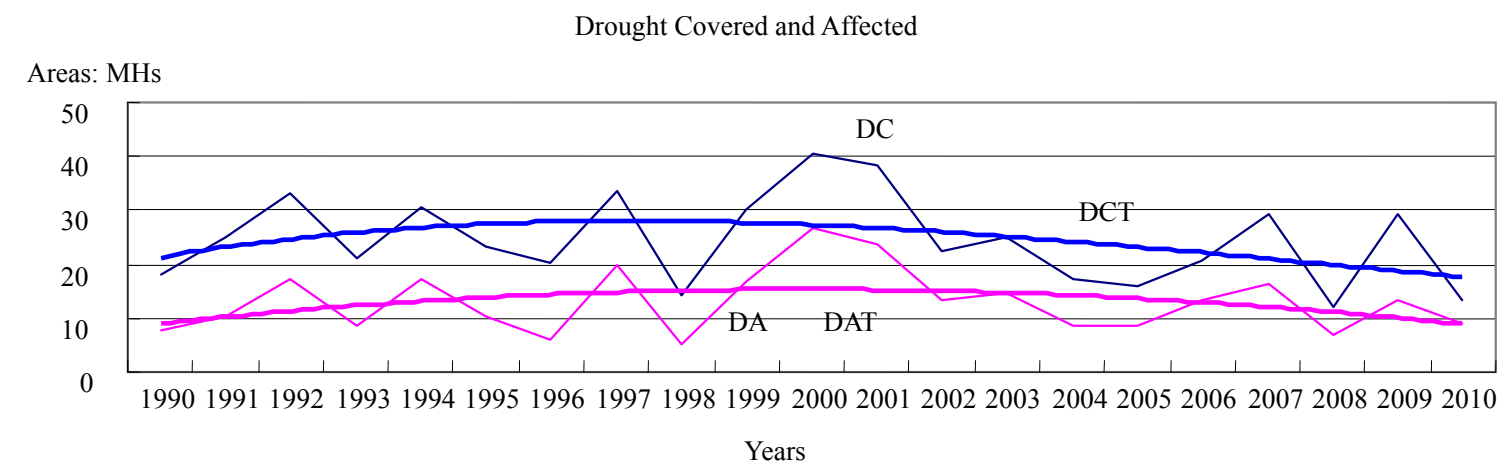

Figure 3. The variation of drought had covered and affected area since 1990s

Areas: MHs

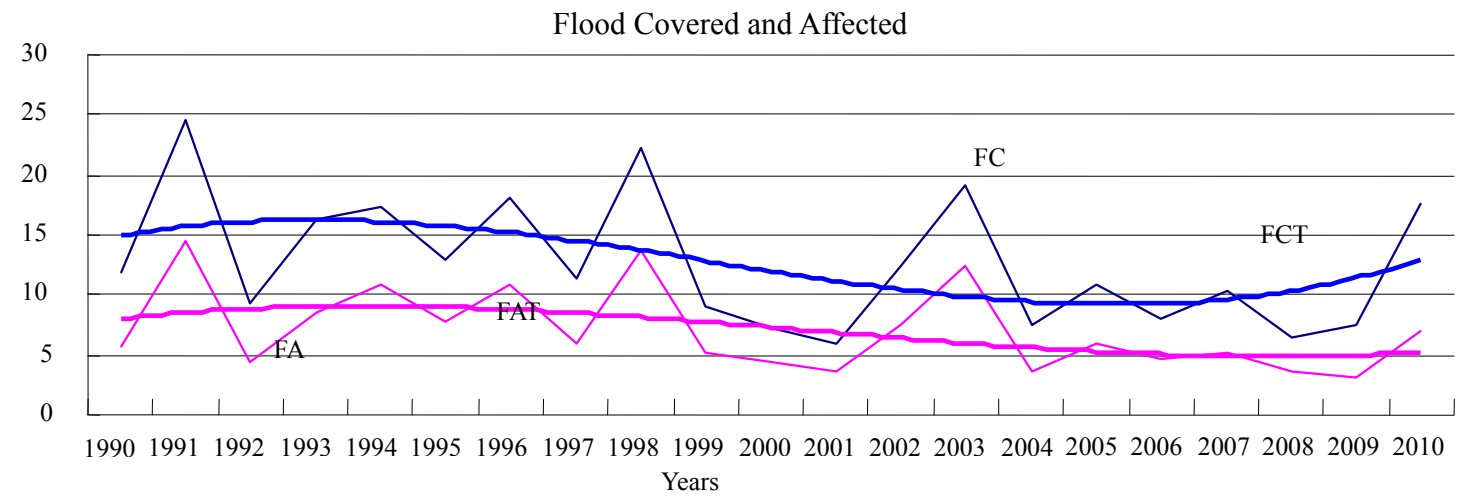

Figure 4 . The case of flood covered and affected in past 21 years 


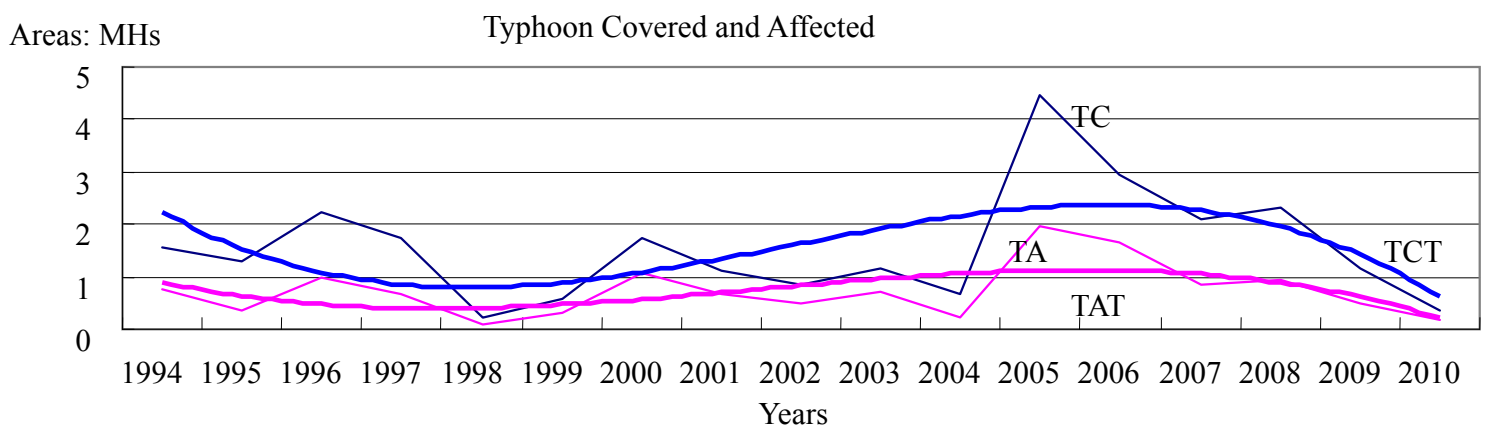

Figure 5. The situation of typhoon covered and affected over 17 years

Freezing, wind and hail reduction trends

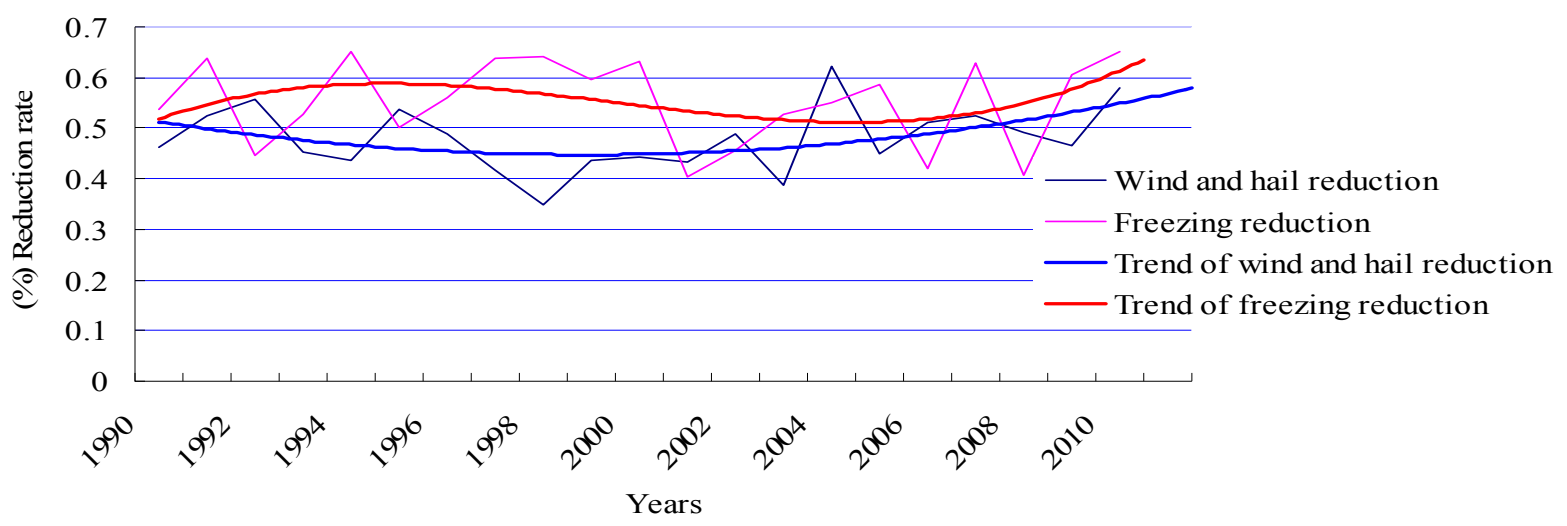

Figure 6. Trends on reduction of freezing, wind and hail

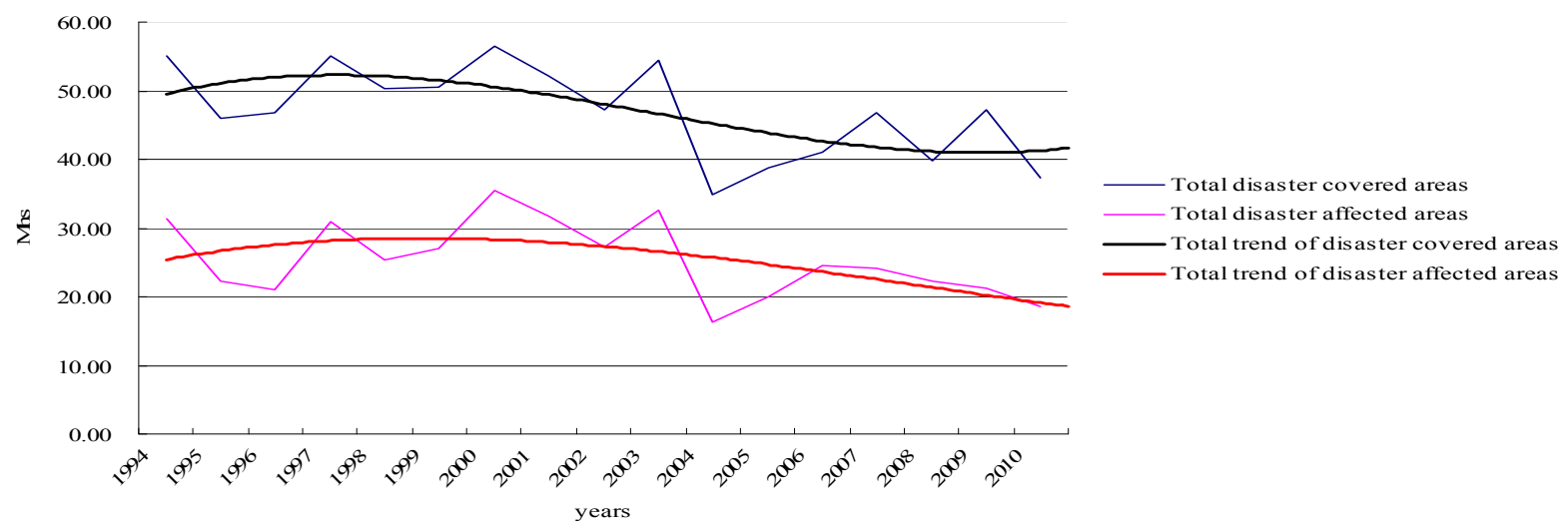

Figure 7. Total natural disaster covered and affected area and their tendencies 


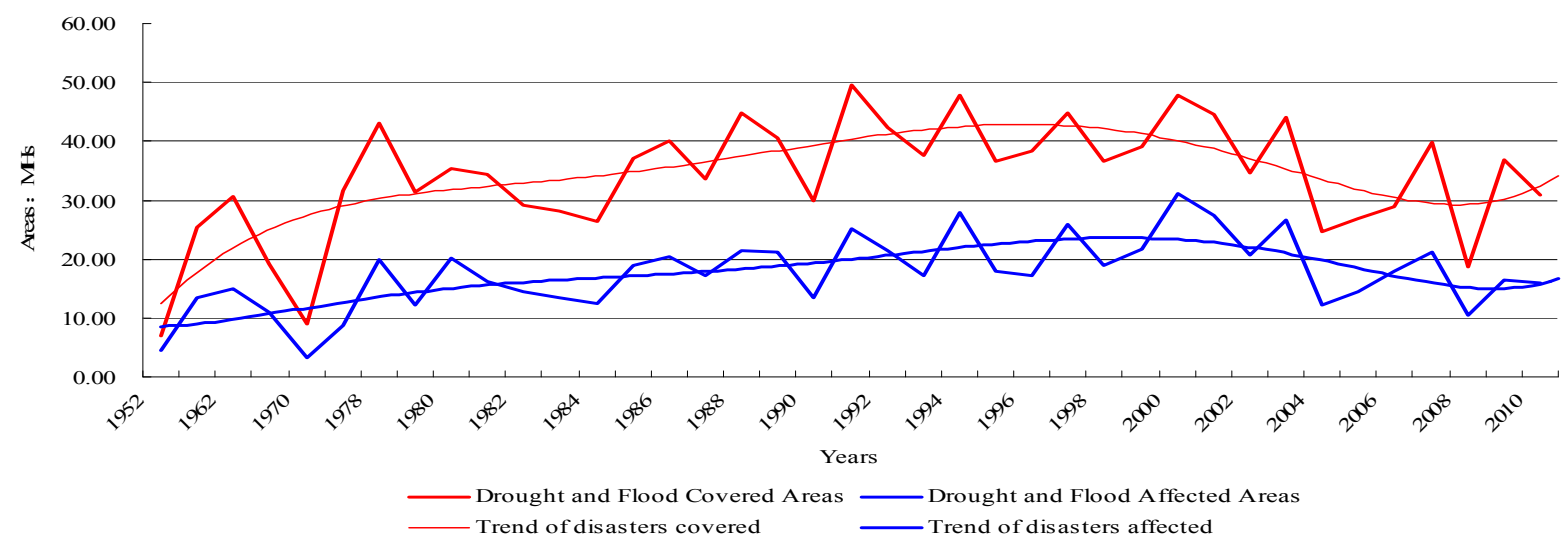

Figure 8. A long-term tendencies for the main disasters drought and flood since 1952

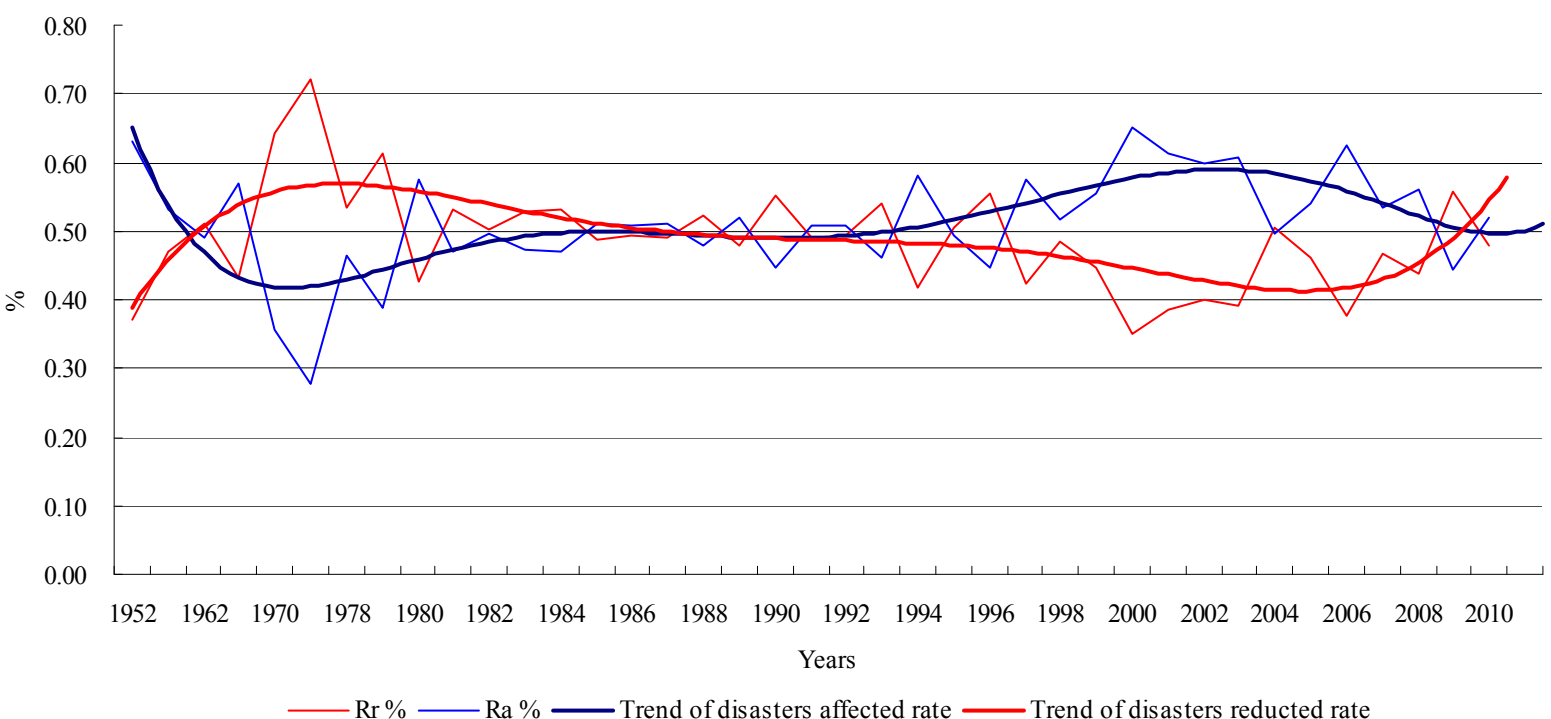

Figure 9. Variations of disaster reduction rate and affected rate for droughts and floods since 1952 